\title{
LA POBLACIÓN DE MANILA Y LAS CAPELLANÍAS DE MISAS DE LOS ESPAÑOLES: LIBRO DE REGISTROS, 1642-1672*
}

\author{
POR \\ JUAN MESQUIDA OLIVER \\ University of Asia and the Pacific
}

Este estudio se centra en las características de las capellanías de Manila hasta 1672. Para ello se utiliza la documentación proveniente de un libro de registros de capellanías. Además de exponer el desarrollo de esa institución, la información cuantitativa y cualitativa recabada sirve para estudiar aspectos demográficos, sociales, culturales y económicos de la población española de Manila durante una buena parte del siglo XVII. Entre las novedades presentadas sobresalen los esfuerzos realizados y las dificultades encontradas para crear un clero criollo.

Palabras Clave: Manila, siglo XVII, capellanías, españoles, clero criollo.

\section{INTRODUCCIÓN}

El capitán Hernando Ramírez Plata mandó fundar la primera capellanía de Manila en 1583, tan sólo doce años después que el adelantado Miguel López de Legazpi estableciera la ciudad en la orilla izquierda de la desembocadura del río Pásig. Pasarían casi veinte años hasta que otro español fundara la siguiente capellanía y, desde entonces, se fundaron muchas más a lo largo del siglo XVII. Un libro de registros de capellanías del arzobispado de Manila, cumplimentado entre 1642 y 1672, suministra un buen número de expedientes con los que estudiar el uso que se hizo de esta institución. Desde la perspectiva inédita de ese libro, utilizado aquí por primera vez de una manera exhaustiva,

* El autor desea agradecer a María Pilar Martínez López-Cano las sugerencias que ofreció a una versión temprana de este artículo. 
este trabajo aporta una nueva dimensión a la cada vez más abundante bibliografía sobre la sociedad española de Manila en el siglo XVII. A través de la documentación sobre capellanías, se puede estudiar cómo los españoles que se establecieron en Manila llevaron consigo los modos de vida e instituciones de México y España. La misma fuente es útil para abordar facetas de la historia demográfica, social, cultural y económica de la comunidad española de la ciu$\mathrm{dad}^{1}$. Para comprender el valor de la nueva información proveniente del libro de registros conviene describir, aunque sea someramente, el desarrollo de la población española en la mayor parte del siglo XVII, ya que hay una clara relación entre las dos.

La importancia de las capellanías en Manila es útil para valorar el esfuerzo de la Corona por conseguir en Filipinas una comunidad española estable, aunque fuera reducida en número. El virrey de Nueva España estaba obligado a remitir contingentes de soldados y pobladores, aunque no siempre lo hacía. Éstos fueron especialmente numerosos con la llegada de cada gobernador general. Por ejemplo, en 1575 el gobernador Francisco de Sande llevó 350 personas, soldados y oficiales en su mayoría, de los cuales 34 iban con sus mujeres. En 1578, la expedición de Gonzalo Ronquillo salió de España con un contingente numeroso de labradores y artesanos. Aunque algunos se quedaron en América, Ronquillo consiguió formar una comunidad española sólida en Manila, fundamentada en familias con hijos menores de edad. El esfuerzo se continuó hasta la tercera década del siglo XVII, y de una manera especialmente sostenida en la última década del siglo XVI, en la que un $12 \%$ de los pobladores eran niños que iban con sus padres ${ }^{2}$. De esta forma, la población española de Manila fue creciendo, aunque es difícil describir el proceso con exactitud por la imprecisión de las fuentes en materia demográfica. Éstas se refieren unas veces a los vecinos o propietarios de las casas de la ciudad, sin especificar el número de personas a que correspondían, y otras dan cifras generales sobre la población española. Así, en 1570 una fuente dice que había unas cincuenta familias en Manila; en 1586 un documento habla de 70 vecinos, mientras que otro menciona que había 180 vecinos al año siguiente. En 1591 se creía que Manila tenía 300 vecinos y en 1601 se dio la cifra de 1.500 españoles

1 Esta contribución enlaza con trabajos parecidos sobre diversas regiones de España y América. Como una introducción a esos trabajos y para conseguir una bibliografía inicial, se recomienda García-Abásolo, «El mundo privado de los pobladores de la América española», Ámbitos, 16 (Córdoba, 2006): 17-30.

2 García-Abásolo, 1997: 144-151; 19/20 (Madrid, 2006-2007): 141-147. Filipinas fue parte del impulso poblador de la Corona en América durante el mismo período; García-Abásolo y Peláez, 2007: 24-25. 
para todo el archipiélago. Además, cuando las fuentes hablan de vecinos no incluyen a los soldados ni al clero regular ${ }^{3}$.

En las primeras décadas de su historia, Manila tuvo que hacer frente a bastantes obstáculos que impidieron el crecimiento de su población. Aparte de las dificultades ambientales de adaptación al clima tropical, Manila sufrió los percances siguientes que causaron muchas bajas: los incendios de 1583 y 1603 , un terremoto en 1600, una batalla naval con los holandeses cerca de Manila ese mismo año, y un alzamiento chino en $1603^{4}$. Todos esos infortunios contribuyeron a crear una mala publicidad acerca de las islas que dificultó el reclutamiento de nuevos pobladores. A pesar de ello, continuó el plan poblador de manera sistemática, como ya se ha indicado, y fueron bastantes familias hasta 1630, si bien en menor número que en el siglo anterior. Manila siguió creciendo, de manera que una fuente de 1612 menciona que había 2.800 españoles en las islas; pero desde ese año las noticias reflejan un estancamiento demográfico, ya que se contaron 295 vecinos en 1617, y el censo de 1634 registró 283 vecinos. Desde entonces, las cifras empezaron a bajar rápidamente: en 1638 había 90 vecinos y a partir de 1655 las fuentes hablan de 30 vecinos. Esa situación duró hasta los últimos decenios del siglo, cuando se inició una recuperación ${ }^{5}$.

Las causas del descenso de la población son muchas y complejas. Como telón de fondo están las dificultades experimentadas en el archipiélago, que no creaban muchos alicientes para nuevos pobladores, sobre todo si se compara con las posibilidades que ofrecía la Nueva España. La emigración de artesanos o labradores no cuajó porque no podían competir con la población china que, atraída por la plata de México y la actividad económica de Manila, llegaba a muchos millares y monopolizaba esos tipos de trabajo. La indisposición de la clase alta hacia la agricultura y las dificultades de la explotación de la tierra y la minería, también contribuyeron a que no hubiera mayor emigración. Aunque se buscó la merced real para prosperar, como se hacía en América, no dio el mismo resultado porque la encomienda o el oficio público no fueron garantía de riqueza, salvo casos excepcionales. Mejor resultado dio la distribución de boletas entre los vecinos de la ciudad para el comercio del galeón de Manila, que llevaba los codiciados productos chinos a Acapulco y se convirtió prácticamente en el único incentivo para atraer y retener a los pobladores, como pretendía la Corona. Sin embargo, sus efectos fueron reducidos, porque pronto

3 Merino, 1983: 24-36. Alva Rodríguez, 1997: 26-36. García-Abásolo, XXXII / 125 (México D.F., 1982): 57.

4 Díaz-Trechuelo, 1984: 129, 138.

5 García-Abásolo, 1997: 144-145. Merino, 1983: 24-36. Alva Rodríguez, 1997: 26-36. 
se pusieron límites a la carga de mercancías, impidiendo un incremento progresivo del comercio, y también porque se formaron redes de comerciantes establecidos en México alrededor del comercio del galeón, con mayores capitales que los pobladores de Manila y con los que era difícil competir. Las inspecciones y restricciones del visitador Pedro de Quiroga al tráfico del galeón en Acapulco, causaron que hubiera poco comercio entre 1636 y 1640; agravando la falta de incentivos para los posibles pobladores de Filipinas durante esos años.

Otra serie de calamidades contribuyeron a la disminución de la población, tanto por las víctimas como por el desánimo que produjeron. El segundo y tercer alzamientos chinos en 1639 y 1662-1663 hicieron crecer el recelo y el temor de los españoles hacia esa población. Un terremoto de gran magnitud destrozó Manila en 1645, dejando la ciudad con un aspecto deplorable durante bastantes años. Otros terremotos en 1654, 1677 y 1688 mantuvieron su fama de ciudad peligrosa. Manila también sufrió ataques de los holandeses, con los que hubo un estado de guerra hasta la mitad del siglo XVII. Estos contratiempos explican los elevados índices de mortalidad de los españoles; pero además la población española de Manila se caracterizó por unas tasas de natalidad muy bajas, quizá por la falta de adaptación al clima, e incluso debido a razones psicológicas por los problemas mencionados. A todo lo dicho hay que sumar el declive demográfico general de España en el XVII, que provocó una baja de la emigración a América, especialmente desde mediados de siglo, y que también afectó a Filipinas ${ }^{6}$.

Después de explicar el desarrollo demográfico de la población española de Manila en el siglo XVII, es necesario abordar brevemente el perfil social de la ciudad, porque será de utilidad para analizar la información proveniente del libro de registros de capellanías. Manila tenía una oligarquía económica y política, compuesta por los primeros pobladores de la expedición de Legazpi y otros que llegaron después y se distinguieron por hazañas de guerra. Otras formas de acceder a esa elite fueron un matrimonio conveniente, el favor del gobernador, o hacerse ricos con el comercio del Galeón. Muchos de este grupo formaron parte del cabildo de la ciudad. Debido a la alta mortandad masculina causada por las guerras y alzamientos, hubo un número notorio de viudas. El censo de 1617 indicaba que había 65 viudas. Algunas de ellas, y otros españoles venidos a menos, se convirtieron en pobres vergonzantes. La Hermandad de la Casa de la Misericordia de Manila se ocupaba de socorrer a ese tipo de

6 Merino, 1983: 39-54. García-Abásolo, XXXII / 125 (México D.F., 1982): 62-75; 44 (Manila, Third Quarter 1996): 361-364; 19/20 (Madrid, 2006-2007): 136-138. Manchado López, 2008: 141-159. Díaz-Trechuelo,1984: 134-137, 139-146. 
personas, y también a los esclavos y sirvientes de los españoles cuando enfermaban. Un elemento fundamental de la vida de Manila, y de las Filipinas en general, era la presencia del clero regular. Las órdenes religiosas fueron las responsables de la cristianización de las islas y sus miembros funcionaron como representantes de la autoridad real en las zonas rurales. En Manila tenían espaciosas iglesias y conventos. Fueron siempre muy numerosos comparados con el escaso clero secular ${ }^{7}$.

\section{LAS FUENTES}

La fuente utilizada es el único libro de registros de capellanías del siglo XVII que sobrevivió a los avatares de la Segunda Guerra Mundial en el archivo del arzobispado de Manila. Contiene, excepto en un caso, las capellanías que fundaron los españoles servidas por el clero secular. Este libro es fruto de los esfuerzos del juez de testamentos y capellanías Pedro Díaz de la Rivera en 1642 , y de otros jueces alrededor de 1650 y 1672, con la intención de recabar documentación más detallada para que los capellanes pudieran formalizar sus beneficios ${ }^{8}$.

Antes de empezar a desgranar las noticias provenientes de la documentación, es necesario dar una visión sucinta del funcionamiento de la institución. La capellanía de misas era un acto legal por el que una o varias personas, los fundadores, disponían de unos bienes económicos con el fin de crear un capital, el principal, para que generase unos réditos o renta permanente con la que pudiera mantenerse un sacerdote, el capellán. Éste tenía la obligación de celebrar a perpetuidad un número determinado de misas cada año, a modo de sufragio por las almas estipuladas por los fundadores. Al ser una fundación perpetua, requería una figura supervisora para que no se extinguiese la renta y siempre hubiese un capellán para celebrar las misas. Esa persona era el patrón de la capellanía, que era nombrado por los fundadores. Éstos solían dejar instrucciones para que siempre hubiera un patrón al fallecer el anterior. Uno de los instrumentos más usados para crear una renta con un principal fue la imposición de censos, como luego se verá. Por el carácter espiritual de la obliga-

7 Alva Rodríguez, 1997: 34-36, 332-338. Merino, 1987: 77-93. Manchado López, 2008: 146. García-Abásolo, XXXII / 125 (México D.F., 1982): 78-79. Díaz-Trechuelo, LIII / 107 (Madrid, 2001): 352-355.

8 Pniover, 1954: 67-75, 140-146. La diócesis del arzobispado de México había realizado la misma tarea de control y regulación veinte años antes, en 1620; Martínez López-Cano, 2004: 139-143. 
ción, los bienes donados pasaban a ser de jurisdicción eclesiástica9 ${ }^{9}$ La fundación se podía efectuar en vida de los fundadores o, como sucedió con frecuencia, en los actos testamentarios ya al final de su vida y en previsión de una ayuda espiritual para el más allá.

En la capellanía se puede observar una fusión de realidades espirituales y materiales. Por un lado sobresalen las creencias acerca de la vida después de la muerte y de la eficacia de la oración, especialmente de la misa, para los que debían expiar sus penas temporales en el purgatorio. Por el otro, había un principal, una renta y un contrato de censo. Las dos realidades dependían la una de la otra en una armonía que no extrañaba a la mentalidad de los protagonistas ${ }^{10}$. Además de lo estrictamente relacionado con el fin religioso de la capellanía, el fundador podía utilizar la realidad material de ella para ayudar económicamente a terceros al permitir que parte de la renta fuese para ellos. En muchos casos se trataba de financiar los estudios eclesiásticos de aspirantes al sacerdocio, aunque también podía servir para mantener a un laico económicamente. Con su elección de capellán, el estudiante o el laico, tenían la obligación de dedicar parte de la renta que recibían al estipendio que tenían que pagar para que un sacerdote dijera las misas establecidas por el fundador ${ }^{11}$.

En el libro objeto de este estudio, los documentos presentados por los capellanes proporcionan información sobre las capellanías desde el principio del XVII. Se deja aparte por ahora otra información que provendrá del estudio de otros libros de capellanías del siglo XVIII, y sobre las capellanías fundadas por los españoles e indígenas, pero servidas por las órdenes religiosas.

\section{LOS FUNDADORES}

El libro recoge información de cuarenta y siete capellanías casi con completa seguridad. El cuadro I del apéndice muestra la lista de los fundadores, con unas breves pinceladas sobre sus posiciones sociales y las cantidades que dejaron como principal. Este elevado número indica que se produjo un buen transplante del estilo de vida venido de México y España ${ }^{12}$.

9 Para una explicación más detallada sobre las capellanías se recomiendan García-Abásolo, 1983: 427-453, destacando en estas fundaciones su función como entidades de crédito, y los estudios presentados en Cofradías, capellanías y obras pías en la América colonial, Martínez López-Cano, Von Wobeser y Muñoz (ed.), 1998. Los que dan una visión más de conjunto sobre esta institución son: Von Wobeser, 1998: 119-130, y Montero Recorder, 1998: 131-142.

10 Estas ideas han sido estudiadas para las cofradías por Lavrin, 1998: 49-64. El planteamiento es también válido para las capellanías.

11 Levaggi llama la atención del papel asistencial de las capellanías, 1998: 143-154.

12 El fenómeno se extendió rápidamente a la población indígena recién convertida. La pri- 
Lo primero que destaca al mirar la lista de las capellanías, es que el proceso de fundación de capellanías tuvo un comienzo lento, porque en los primeros treinta años desde la fundación de Manila sólo aparece la ya mencionada capellanía de 1583. No es de extrañar que fuera así, ya que los comienzos fueron difíciles para la población española y sobre todo porque para la mayoría, a pesar de sus deseos de establecerse en la ciudad, lo normal sería que preservasen una mayor afinidad con sus lugares de origen en España y Nueva España ${ }^{13}$. Fue necesario esperar una generación para que la fundación de capellanías tomara ímpetu. Sin embargo, el flujo de fundaciones de capellanías no se detuvo entre 1606 y 1639 . El hecho de que no hubiera períodos largos sin que se fundaran capellanías refleja la normalidad de vida de la comunidad española de Manila, ya que solamente aquellos que se habían asentado física y sentimentalmente en la ciudad tendrían interés por sustentar a su clero. Además, las fundaciones contribuyeron indirectamente a atraer pobladores mediante ese reflejo de desarrollo normal de la comunidad, porque fundando capellanías expresaban su confianza en permanecer y en dejar formas de vida para un linaje. Se observa una disminución en el número y frecuencia de fundaciones desde 1639 , que se puede atribuir a las dificultades demográficas causadas por el alzamiento chino, las restricciones en el comercio del galeón por parte de Quiroga, el terremoto de 1645 y el declive general de la población hasta las últimas décadas del siglo. Así se nota que aunque el libro de registros recoge fundaciones sólo hasta 1672, son muy pocas las que se fundan después de 1650 .

El rasgo más sobresaliente en el conjunto de los fundadores es la predominancia femenina. Hay diez viudas y otras ocho mujeres de las que no se especifica su estado. Ocho matrimonios fundaron una o dos capellanías. Entre la población masculina no casada hay cinco eclesiásticos con cargos diferentes en la catedral y un licenciado candidato al sacerdocio. No sabemos el estado de trece varones. El muestrario es representativo de los esfuerzos para establecer una comunidad española en Manila expuesto anteriormente. La abundancia de viudas es fácil de explicar, aparte de la natural longevidad de las mujeres, si se consideran los frecuentes encuentros armados y calamidades que experimentaron los habitantes de la ciudad, sobre todo si eran hombres de guerra. La repetida presencia de viudas entre los fundadores también responde a factores económicos, porque era frecuente que el matrimonio planificase la

mera capellanía fundada por un indígena fue en 1592 para un sacerdote agustino en la provincia de Pampanga. Todavía hubo que esperar hasta 1699 para que se fundara la primera capellanía para beneficio de un capellán no español o criollo. El beneficiado fue el mestizo de chino José de Ocampo; Santiago, 2001: 1-4; XXII / 66 (Manila, 1987): 422-423, 433.

13 García-Abásolo, 44 (Manila, Third Quarter 1996): 360-361. 
fundación de la capellanía, pero también que no hubiera dinero disponible hasta después del fallecimiento del marido. Se comprende que los eclesiásticos fundaran capellanías para recibir ayuda espiritual y también para contribuir al sustento del clero de la ciudad.

El nivel social y económico de los fundadores fue mayoritariamente alto. Destacan un oidor, dos maestres de campo, dos generales, cuatro regidores y cuatro oficiales del ejército. Entre las viudas, tres lo eran de generales o almirantes, una de escribano, otra de oficial y dos de regidores. De las otras mujeres, una estaba casada con un sargento mayor y otra con uno que sería alcalde más tarde. Sin embargo, hay tres situaciones de gente con menos recursos ${ }^{14}$.

El principal de estas fundaciones, en dinero o en bienes para su venta, alcanzó cantidades generosas. La media del principal de las 45 capellanías en las que es conocido es de 2.613 pesos, es decir, una cantidad considerable si tenemos en cuenta los grandes reveses de fortuna típicos de los habitantes de Manila ${ }^{15}$. El cuadro 1 distribuye los principales según las cantidades de su monto. El que haya una gran mayoría de fundaciones con cantidades elevadas concuerda con la categoría social alta de los fundadores, indicada anteriormente. Por otro lado, el reducido número de capellanías con montos pequeños puede significar que un gran sector de la población no tenía suficiente dinero ni para pensar en semejante obra pía, o que los españoles de medios más modestos no se sintieron adaptados a la ciudad.

Cuadro 1. Principales de fundación de las capellanías

\begin{tabular}{|l|c|c|}
\hline \multicolumn{1}{|c|}{ Cantidades (en pesos) } & Número de casos & Porcentaje \\
\hline Menos de 330 & 3 & 6,66 \\
De 1.000 a 1.999 & 14 & 31,11 \\
De 2.000 a 2.999 & 12 & 26,66 \\
De 3.000 a 3.999 & 10 & 22,22 \\
Más de 4.000 & 6 & 13,33 \\
\hline
\end{tabular}

14 Capellanías. Cargo y data, Archdiocesan Archives of Manila (AAM), Manila, General Administration / Archbishop of Manila, Capellanías, legajo 9.D.10., fols. 122v-124v. Desde ahora se citará como Capellanías de Manila del Siglo XVII (CMSXVII).

15 En la ciudad de México, que era una ciudad mucho más rica que Manila, entre 1570 y 1640 la media de los montos de fundación de capellanías se situó entre 2.901 y 3.110 pesos. Debido a la baja obligatoria de los interés de censo en 1608 hubo un aumento general de los montos desde entonces en México; Martínez López-Cano, 2004: 153 y Cuadro 8. 
La mayoría de los fundadores, treinta y uno, se decidieron a disponer la fundación de capellanías en sus testamentos, poco antes de morir, y en varios de esos casos se especifica que estaban enfermos. Podrían ser más, ya que la documentación no es completa. Es natural que cuando presentían la cercanía de la muerte se esmerasen por dejar las cuentas en regla con el Altísimo; como el canónigo Diego de León, que dejó sus posesiones para que se celebraran misas por su alma y para dar limosnas a los pobres, pero también incluyó una capellanía con el propósito de reparar por las obligaciones que dejó incumplidas y así tener más fácil acceso al cielo ${ }^{16}$. Además de las razones religiosas, se entiende que la fundación se dispusiera poco antes de la muerte, por la inseguridad económica que prevalecía en las islas, y con más razón en el caso de las numerosas viudas.

\section{LOS PATRONOS}

Uno de los elementos más importantes en la fundación de una capellanía fue la elección del patrón. Esta figura tenía varias obligaciones de las que dependía la existencia y el futuro de la capellanía. Le correspondía todo lo relacionado con las inversiones que producía la renta que se daba al capellán. Como la manera más común de generar esa renta era a través de un censo consignativo, el patrón tenía el deber de asegurar que el censatario tenía buen cuidado de las propiedades del censo, para que así mantuvieran el valor real que permitía recaudar la renta asignada por el fundador. Además, el patrón tenía que procurar que el capellán cumpliera su parte de la capellanía, celebrando las misas a las que se había obligado al aceptarla. Por eso el fundador de la capellanía sopesaba cuidadosamente en quién debía recaer tal responsabilidad. En una situación como la de Manila en el siglo XVII, en la que un gran número de los pobladores carecía de parientes debido a las bajas cotas de natalidad y a la elevada mortandad, con la consiguiente extinción de familias en pocas generaciones, es comprensible que muchos de los fundadores buscaran la estabilidad futura de sus capellanías, nombrando patronos de sus capellanías a instituciones de Manila, en lugar de escoger a personas determinadas. Así sucedió con el 35,5\% de los fundadores: seis encomendaron el patronazgo al arzobispo, tres casos al deán y cabildo de la catedral, dos a la Hermandad de la Misericordia, dos al provincial de los agustinos, dos al rector del colegio de los jesuitas y uno al prior del convento de Santo Domingo. Como estas institu-

16 CMSXVII, fols. 85r-90v. 
ciones inspiraban suficiente confianza de que preservarían las capellanías en el futuro, los fundadores no vieron la necesidad de especificar un segundo o tercer patrón en el caso de que ellas fallaran en su cometido.

Seis de los fundadores decidieron nombrarse patronos ellos mismos, pero la mayoría de ellos dispusieron que a su muerte hubiera patronos más permanentes, como el arzobispo, el provincial de los franciscanos y el prior de Santo Domingo. El tenor de las disposiciones revela que había fundadas aprensiones de que sus familias no se perpetuarían. Algo parecido se entrevé en las indicaciones de los fundadores que dejaron como primeros patronos a sus parientes, amigos o incluso a personas de las que no sabemos qué relación tenían con los fundadores, porque la segunda opción también recayó en instituciones o cargos institucionales.

Los arzobispos de Manila también estuvieron al tanto de las capellanías de patronazgo irregular para adjudicárselas en cuanto hubiera oportunidad. Así aparecen cinco casos de capellanías en las que el arzobispo asumió la función de patrón. En uno porque el patrón era un sacerdote que no le había pedido permiso y en otros dos porque los patronos retardaron el nombramiento de los capellanes. En el caso de la capellanía que fundó la señora Méndez en el Puerto de Cavite, el arzobispo lo asumió porque no había dispuesto patrón. El matrimonio formado por Juana Suárez y Andrés de Alcaraz dejaron a parientes como patronos. Como el matrimonio no dejó descendientes, en 1626 el arzobispo Miguel García Serrano (O.S.A.), se apresuró a hacer una nueva fundación asumiendo el patronazgo hasta que apareciera algún pariente legítimo. Como el monto del principal de la capellanía era grande, 10.000 pesos, el arzobispo fundó tres capellanías de coro, en las que los capellanes tendrían la obligación de asistir a los cantos del coro de la catedral los domingos, días festivos y otros días con sermones. De esa manera se solucionaba el problema de asistencia a esos actos ${ }^{17}$. Era lógico que el arzobispo ejerciera su autoridad para conseguir control sobre las capellanías, ya que entre sus primeras obligaciones se incluían la conservación del culto divino y el sostenimiento de sus sacerdotes. Hay que considerar que el clero secular era muy minoritario comparado con el regular, y con unas fuentes de ingresos mucho más reducidas que las de los religiosos.

El cuadro 2 recoge los últimos patronos de las capellanías. Se comprueba que casi todas acabaron en las manos de las autoridades eclesiásticas, las órdenes religiosas o la Mesa de la Misericordia, que juntas suman el 80,85\% del total, y se puede inferir que las otras nueve capellanías, de las que carecemos de información suficiente, también acabarían tarde o temprano en las mismas

17 CMSXVII, fols. 9r-14v. 
Cuadro 2. Preferencias en El nombramiento de patronos

\begin{tabular}{|c|c|c|c|c|c|}
\hline & $\begin{array}{l}\text { Primer } \\
\text { patrón }\end{array}$ & $\begin{array}{l}\text { Segundo } \\
\text { patrón }\end{array}$ & $\begin{array}{l}\text { Tercer } \\
\text { patrón }\end{array}$ & $\begin{array}{l}\text { Adjudi- } \\
\text { cadas }\end{array}$ & $\begin{array}{l}\text { Último } \\
\text { patrón }\end{array}$ \\
\hline Arzobispo & 6 & 3 & 1 & 5 & 15 \\
\hline Deán y Cabildo & 3 & 4 & 1 & & 8 \\
\hline Mesa de la Misericordia & 2 & 4 & 1 & & 7 \\
\hline Provincial de los agustinos & 2 & & & & 2 \\
\hline $\begin{array}{l}\text { Rector del colegio de los je- } \\
\text { suitas }\end{array}$ & 2 & 1 & & & 3 \\
\hline Prior de Santo Domingo & 1 & & 1 & & 2 \\
\hline $\begin{array}{l}\text { Provincial de los francisca- } \\
\text { nos }\end{array}$ & & & 1 & & 1 \\
\hline Los fundadores mismos & 6 & & & & 0 \\
\hline Parientes & 9 & 3 & & & 3 \\
\hline Prebendados de la catedral & 5 & & & & 0 \\
\hline Los capellanes & 1 & & & & 0 \\
\hline Sin nombrar & 1 & & & & 0 \\
\hline $\begin{array}{l}\text { Personas sin relación cono- } \\
\text { cida con los fundadores }\end{array}$ & 5 & 1 & & & 0 \\
\hline Se desconoce & 4 & 2 & & & 6 \\
\hline Total & 47 & & & & 47 \\
\hline
\end{tabular}

manos. Las cifras son elocuentes de la influencia de las características demográficas de Manila en la elección de patrón, y de que la población era muy consciente de esa situación.

\section{LAS MISAS}

La economía espiritual de la capellanía se centraba alrededor de las misas que los fundadores querían que se dijeran por ciertas almas. La creencia en la necesidad y eficacia de la oración por los difuntos se remonta a los primeros siglos del cristianismo. San Agustín recomendaba que se rezaran oraciones, se ofreciera la misa y se dieran limosnas para ayudar a las almas que sufrían penas de purgatorio. El término "purgatorio» se afianzó en los concilios ecuménicos de la Edad Media ${ }^{18}$. Para la Iglesia Católica, la misa es la oración que, por ser el sacrificio de Jesucristo, tiene más eficacia para rescatar a las almas del purgatorio. Así lo expresó, y era una creencia común, la Mesa de la Miseri-

18 Mateo Seco, 1974, vol. XIX: 507-511. 
cordia de Manila cuando aceptó el patronazgo de la capellanía fundada por el maestre de campo Don Pedro de Heredia y su mujer.

«Dijeron que por cuanto de fundarse capellanías se aumenta el culto divino, y con las misas que los constituyentes y fundadores de ellas mandan decir, y se dicen, reciben sufragio las ánimas del Purgatorio, a las cuales la ley de la caridad nos obliga a socorrer, atento a lo cual y considerando que el sacrificio de la Misa es el más acepto y agradable al Padre eterno y la ofrenda más preciosa que se le puede ofrecer» ${ }^{19}$.

Los efectos espirituales de las misas ofrecidas por las almas de las personas indicadas por los fundadores eran, por lo tanto, el objetivo principal de la capellanía. La mayoría de las veces, los fundadores disponían que las misas se ofrecieran primariamente por sus propias almas. Así sucedió con las 32 capellanías de las que se posee información en esta materia. Después de sus propias almas, los fundadores se acordaron en algunos casos de personas a la que estaban unidos emotivamente. El cuadro 3 recoge las ocasiones en las que aparecen las personas por las que se debían ofrecer las misas, aunque es preciso consignar que una capellanía podía incluir hasta cuatro o cinco tipos de personas.

Cuadro 3. Allegados que el fundador quería Que Se incluyeran EN LAS MISAS DE SU CAPELLANÍA

\begin{tabular}{|l|c|}
\hline \multicolumn{1}{|c|}{ Tipo de relación } & Número de veces \\
\hline Padres & 16 \\
Madre & 2 \\
Marido & 6 \\
Esposa & 1 \\
Hijos & 1 \\
Parientes, sin especificar & 13 \\
Abuelos & 2 \\
Primos & 1 \\
Sobrinos & 1 \\
Bienhechores y amigos & 3 \\
Albaceas & 1 \\
Ánimas del Purgatorio & 7 \\
\hline
\end{tabular}

Hasta cierto punto era normal que se pensase primero en los parientes fallecidos, pero como la capellanía tenía un carácter perpetuo, se podían incluir

19 CMSXVII, fols. 38r-39v. 
familiares más jóvenes. Sin embargo, las preferencias de Manila en el XVII parecen tener relación con el desarrollo demográfico de la ciudad. La preocupación por padres y maridos refleja la abundancia de solteros y viudas. Pero lo que es más llamativo es que se mencione a los hijos solamente una vez, y que algunos piensen en sus primos y sobrinos, que son un parentesco fuera de la familia inmediata, o que se acuerden simplemente de los parientes en general. Esas intenciones concuerdan una vez más con la alta tasa de mortalidad y el bajo índice de natalidad de la sociedad española de Manila. El recuerdo de sus maridos, en las intenciones de una de las fundadoras, es un testimonio de un fenómeno frecuente en la Manila de entonces: el casamiento de viudas en segundas nupcias con españoles de reciente arribada y con deseos de subir en la escala social rápidamente ${ }^{20}$.

Las disposiciones que acompañaban la creación de una capellanía establecían otra clase de detalles, como el número de misas que debería celebrar el capellán, y en algunos casos se indicaban también los días en los que el fundador prefería que se celebraran esas misas, e incluso la iglesia o el altar de su preferencia. El número de misas venía regulado por el monto del principal de la fundación de la capellanía, el interés de la renta de ese principal y la normativa del arzobispo sobre el estipendio de cada misa. En general, en Manila en el siglo XVII se movió entre dos pesos y dos pesos y medio por misa rezada ${ }^{21}$. El estipendio de la misa cantada oscilaba entre seis y diez pesos, según la solemnidad que se le diera por medio de la decoración, los cantores y el número de ayudantes.

Para más de la mitad de las fundaciones conocemos los lugares sagrados en los que se debían celebrar las misas de las capellanías. La elección es señal de una relación sentimental de los fundadores con ciertas iglesias, órdenes religiosas o instituciones. El cuadro 4 nos da una idea de la diversidad de las preferencias. En algunos casos incluso mencionaban el altar, con su devoción, en el que querían que se dijeran las misas, como por ejemplo el altar de las ánimas de la catedral, el de San José de la iglesia de la Misericordia, el de la Virgen de Loreto en la iglesia de los jesuitas o el del Santo Cristo en el colegio de San Juan de Letrán. Era común que la preferencia fuese debida a que el fundador estaba enterrado en esa iglesia o a que lo estuviese su marido, esposa o algún familiar.

Resulta lógico que la catedral fuera la sede para las misas del mayor número de capellanías, porque el arzobispo y el deán y cabildo copaban la mayoría

20 Merino, 1983: 47-48.

21 En la diócesis de México la limosna era de un peso y medio o de dos pesos; Martínez López-Cano, 2004: 150. 
CUAdRo 4. Iglesias ESCOGIDAS PARA LAS MISAS DE LAS CAPELLANÍAS

\begin{tabular}{|c|c|}
\hline Iglesias & Capellanías \\
\hline Catedral & 10 \\
\hline Iglesia de los agustinos & 3 \\
\hline San Nicolás, de los recoletos & 3 \\
\hline Iglesia de los jesuitas & 2 \\
\hline Iglesia de San Francisco & 2 \\
\hline Iglesia de Santo Domingo & 2 \\
\hline Santiago extramuros & 2 \\
\hline Iglesia de la Misericordia & 2 \\
\hline Colegio de San Juan de Letrán & 1 \\
\hline San Andrés, en el colegio de Santa Potenciana & 1 \\
\hline Total & 28 \\
\hline
\end{tabular}

de los patronazgos, ya como primero o como último patrón. Lo mismo puede deducirse del proceso de adjudicación de capellanías que los arzobispos efectuaron. Las otras iglesias se reparten las capellanías de un modo homogéneo.

\section{LOS CAPELLANES}

Además de la función espiritual de asegurar a los fundadores las gracias de las misas celebradas por sus intenciones, la capellanía servía para el sustento del capellán. Como explica el teólogo de la escuela de Salamanca Tomás de Mercado, la capellanía no era una compra de bienes espirituales, ya que la misa no tenía precio, lo que se pagaba era la obligación de decirla por una intención específica, por un tiempo fijo y en un lugar determinado 22 . A fin de cuentas se trataba de una ayuda material para que el sacerdote pudiera ejercer su ministerio sacerdotal, pero con unas condiciones impuestas por el fundador. También la capellanía era una ayuda económica importante para los futuros sacerdotes en sus estudios eclesiásticos.

Una vez más, al estudiar las capellanías de Manila hasta 1672, se encuentra que la preferencia de los fundadores, en este caso del capellán, refleja bastante bien el impulso poblador y la situación demográfica del momento. El libro de capellanías proporciona los nombres del primer capellán en cuarenta y dos de los cuarenta y siete casos, los cuales se recogen en el cuadro II del apéndice. De esos cuarenta y dos, hay trece de los que sólo sabemos el

22 Muñoz Correa, 1998: 160-161. 
nombre y su situación eclesiástica, pero no si tenían alguna relación de parentesco u otro tipo con los fundadores. De los veintinueve restantes, hay once, casi un 40\%, en los que los capellanes eran parientes de los fundadores: hijos, como un hijo natural que murió sin ordenarse, sobrinos, un nieto, otros sin identificar su parentesco, e incluso un ahijado sin parentesco directo. En otros tres casos, los fundadores escogieron a los capellanes por motivos de amistad. Seis de las capellanías, el 20\%, recayeron en prebendados. Dos clérigos, que eran patronos de tres capellanías, escogieron a parientes suyos para ellas: el maestrescuela Miguel de Velasco eligió a su sobrino Diego de Velasco, clérigo de menores, para dos de ellas, y el arzobispo Miguel de Poblete a su sobrino José Millán de Poblete, todavía estudiante, para la tercera. Los fundadores que vivían fuera de la ciudad escogieron a los párrocos de las iglesias próximas a sus casas: los pilotos Esteban Soto y Antón Tomás al del Puerto de Cavite, y la indígena Juana Guinto al de la iglesia de la Ermita de Nuestra Señora de Guía. Hay varios casos excepcionales, recogidos a continuación. Lope Félix de Alcarazo nombró patrón de su capellanía a un dominico, ya que se había educado en el colegio para huérfanos de San Juan de Letrán regido por esa orden, y al que había ido a morirse y a recibir sepultura. El licenciado Lucas del Castillo, clérigo de menores, y el deán de la catedral Francisco Martínez de Ras se hicieron capellanes de las capellanías que fundaron ellos mismos. Un caso único entre todas las capellanías de Manila, aunque era más frecuente en otros sitios, fue el nombramiento de capellán por parte de Josefa Arias Girón de su esposo, el capitán Diego de Morales, para que la disfrutara mientras viviera, con la condición habitual en estos casos de pagar a un sacerdote para que celebrara las misas. El cuadro 5 da las cifras y el porcentaje del estado clerical de los primeros capellanes elegidos y si se conoce algún tipo de afinidad con los fundadores.

Cuadro 5. Preferencias En la elección del Primer CAPELlán

\begin{tabular}{|l|c|c|c|c|}
\hline $\begin{array}{c}\text { Condición } \\
\text { de los capellanes }\end{array}$ & $\begin{array}{c}\text { Se conoce la } \\
\text { relación con el } \\
\text { fundador }\end{array}$ & Se desconoce & Total & Porcentaje \\
\hline Estudiantes & 14 & 7 & 21 & 50 \\
Sacerdotes & 5 & 5 & 10 & 23,80 \\
Prebendados & 8 & 1 & 9 & 21,42 \\
Otros & 2 & 13 & 42 & 4,76 \\
\hline \multicolumn{1}{|c|}{ Total } & 29 & & \\
\hline
\end{tabular}


Es significativo que la mitad de las capellanías se fundaron para que aspirantes al sacerdocio tuvieran con qué mantenerse hasta su ordenación y luego en su trabajo sacerdotal. En la mayoría de los casos se especificaba que eran clérigos de menores, lo que indica que tenían planeado llegar al sacerdocio, pero hay otros capellanes de los que sólo se mencionaba que estaban estudiando en la Universidad de Santo Tomás o en el colegio de la Compañía. El elevado número de capellanías para estudiantes muestra el esfuerzo comunitario de la sociedad española de Manila para crear un clero criollo. Así lo expresaron tres de los fundadores al poner la condición de que los capellanes deberían haber nacido en Filipinas. Igualmente se ve esa tendencia al notar que cinco de los fundadores nombraron como segundo capellán a otro pariente todavía joven, y tres escogieron a los hijos de sus amigos. El esfuerzo de los pobladores por subvencionar a los aspirantes al sacerdocio de entre sus parientes por medio de capellanías, responde también a los deseos de consolidar una población española en Manila, manifestados desde el principio e impulsados por la Corona y su virrey en Nueva España. Tener un clero autóctono daría mayor estabilidad al poblamiento español, en vez de tener que depender del clero regular, que era de por sí en esos tiempos un clero de misioneros que continuaba viniendo de España o México. El cuadro II del apéndice muestra cómo el empeño de fundar capellanías para estudiantes para el sacerdocio se sostuvo hasta incluso después del comienzo de la crisis demográfica de la mitad de siglo.

Cuando el capellán todavía no era sacerdote tenía la obligación de dar una limosna a algún sacerdote para que celebrara las misas estipuladas por el fundador, pero a la vez se quedaba con algo de dinero para su propio sostenimiento. Fernando de Carvajal, yerno de los fundadores Antonio de Espinosa y su mujer María de Riaza, y patrón de la segunda capellanía que dejaron, nombró a su hijo José, clérigo de menores en el colegio de Santo Tomás, como capellán. Al nombrarlo incluyó la siguiente fórmula en la que se explica su obligación: «y en el ínterin que éste se ordene de sacerdote, el dicho Joseph de Carvajal, daremos orden que diga las dichas misas y pagando la limosna de ellas lo demás quedará para el susodicho para ayuda de sus estudios» ${ }^{23}$. Esto explica que el arzobispo pusiera un estipendio aparentemente alto para cada misa, de forma que los aspirantes al sacerdocio pudieran utilizar una parte para sus necesidades y dar una limosna, de una cantidad más baja, para que se celebraran las misas.

Si en la elección de los primeros capellanes se observa una preferencia hacia los clérigos de menores, el panorama cambia al observar la selección de los

23 CMSXVII, fols. $115 \mathrm{r}-117 \mathrm{v}$. 
siguientes capellanes por los patronos. El cuadro III del apéndice recoge la lista de los cincuenta capellanes que no fueron los primeros capellanes de las capellanías, y quizá ni siquiera fueron los segundos capellanes, a los que se les concedieron una o varias capellanías. Las fechas en las que se les concedieron, la mayoría después de 1636, reflejan que heredaron las capellanías de otros. De los cincuenta capellanes, treinta y uno $(62 \%)$ eran sacerdotes, doce $(24 \%)$ eran clérigos de órdenes menores, y siete $(12 \%)$ eran prebendados. El mayor número de capellanías otorgado a los sacerdotes y prebendados se explica porque entonces había más patronazgos de capellanías en manos de instituciones, sobre todo el arzobispado y el cabildo eclesiástico, y era lógico que dieran prioridad al mantenimiento del sacerdocio existente. La disminución de capellanías dejadas en manos de candidatos al sacerdocio no significó un menor interés en que hubiera un clero autóctono, porque también se fundaron nuevas capellanías para aspirantes después de 1636. Si se añaden las que se fundaron con ese objetivo antes de 1636, que se pueden ver en el cuadro II del apéndice, se comprueba que había más que suficientes capellanías para los candidatos al sacerdocio entre las capellanías antiguas y nuevas, sobre todo después del declive de la población española de Manila a mitad de siglo.

Aunque la información disponible es muy incompleta, se sabe que hubo bastantes cambios de capellanes. Hasta 1672, ocho capellanías fueron ocupadas por otras dos personas después del primer capellán, y en otras cuatro capellanías, tres personas distintas sucedieron al primer capellán. También hubo capellanes que ocuparon más de una capellanía al mismo tiempo: ocho capellanes recibieron dos capellanías y otro tuvo tres. Es muy probable que a los capellanes que tuvieron varias capellanías les llegara la segunda por su puesto en el cabildo de la catedral. El sacerdote al que se le adjudicaron el número de capellanías más numeroso fue el seleccionado por la Mesa de la Misericordia como capellán de la Hermandad. El veinticuatro de junio de 1671, la Mesa nombró al licenciado Alonso Pérez Doca como nuevo capellán, en sustitución de Mateo Cuenca de Escobar, y se le dieron las escrituras de ocho capellanías en las que la Mesa tenía el patronazgo ${ }^{24}$.

Lo visto sobre la elección de capellanes indica un objetivo doble por parte de la comunidad española: contribuir a la creación de un clero local español y procurar su mantenimiento. El resultado fue discreto, o incluso positivo si se consideran las circunstancias de Manila. No había entonces ningún seminario en la ciudad, y los dos colegios masculinos de la ciudad, el de San José y el de Santo Tomás, de los jesuitas y dominicos respectivamente, eran colegios de

24 CMSXVII, fols. 204r-204v. Algunas de ellas son las mencionadas en el cuadro de fundaciones del apéndice pero otras son de difícil identificación. 
enseñanza general. De ellos salían vocaciones para el sacerdocio, pocas, y también para las órdenes religiosas ${ }^{25}$. El clero secular sólo se ocupaba de la catedral dentro de la ciudad, y de las parroquias de Santiago y del Puerto de Cavite fuera de ella. Fueron sobre todo los institutos religiosos los que rigieron la inmensa mayoría de las parroquias de las islas hasta el final del periodo colonial español, $y$, por lo tanto, no hubo una necesidad inmediata de procurar un clero local ${ }^{26}$. Finalmente, las dificultades de todo tipo que experimentó la población de Manila en la mayor parte del siglo XVII no facilitaron la formación de un clero secular criollo.

\section{LA FINANCIACIÓN A TRAVÉS DE LOS CENSOS}

Se conoce el modo de financiamiento de cuarenta y dos capellanías. Todas se sirvieron de censos para crear la renta del capellán, excepto en la misa de aniversario de Juana Guinto, para la que se cobraban los alquileres de unas propiedades. El censo era una institución de origen antiguo y que tenía varias modalidades. El más usado en esta época, y el que apareció en todos los casos estudiados en Manila, era el censo consignativo ${ }^{27}$. Este censo era un contrato en el que el censualista o acreedor daba un capital, el principal, a un censatario o deudor y éste se comprometía a dar una renta o interés al censualista, a la vez que hipotecaba una propiedad. Se trataba de un medio de crédito o de una inversión, según se refiera al censatario o al censualista. El procedimiento se distinguía del préstamo con interés, que estaba mal visto por considerarse una forma de usura, porque se reconocía como una compra-venta más que como un préstamo. El censualista compraba del censatario el derecho a recibir una renta, mientras que el censatario tenía el derecho a utilizar la propiedad hipotecada. Después del contrato de censo, el censatario perdía cierto derecho a la propiedad censada, equivalente al valor del censo. Esa mentalidad de ser simplemente un inquilino o usuario de su propia casa, por tener impuesto un censo sobre ella, se ve claramente en la fórmula utilizada por el capitán Gonzalo Ronquillo al imponer en 1624 un censo de 1.400 pesos del dinero de la capellanía fundada por Andrés de Alcaraz y su mujer Juana Suárez, al especificar

25 De la Costa, 1967: 133-135, 217, 359. Villaroel, XXXVII / 111 (Manila, Sept.-Dec., 2002): 523-544.

26 Gutiérrez, 1999: 178.

27 García-Abásolo, 1983: 430-431, 447. Para un estudio detallado del censo consignativo en la edad moderna ver Martínez López-Cano, 1995. Desde ahora cuando se utiliza la palabra «censo» se refiere al censo consignativo. 
«cedo, renuncio y traspaso todo el derecho y acción que tengo a las dichas casas en la dicha capellanía y en quien por ella fue parte para que disponga a su voluntad, y le doy posesión de ellas y poder para que la tomen judicial o extrajudicialmente, en el ínterin me constituyo por inquilino $»^{28}$. El censo consignativo también se conocía por censo «redimible y al quitar», lo cual significa que, si el censatario pagaba el principal al censualista, quedaba liberado del pago de la renta y su casa libre de ese censo.

El censo era un medio muy apropiado para que las donaciones para capellanías u otras obras pías se perpetuaran a través de la renta, ya que se basaba en el valor real de una propiedad que en principio tenía un valor perpetuo. Las diversas maneras de entrar en un censo daban gran flexibilidad para hacer operaciones financieras. En la mayoría de los casos vistos relativos a las capellanías, el fundador imponía un censo sobre una casa propia, y si ya existía el censo sobre una casa, cuando alguien la compraba tenía que reconocer el nuevo censo, de forma que en las dos situaciones lo único que hacían era obligarse a pagar la renta de la capellanía, sin tener que desembolsar ninguna cantidad de dinero. Si se vendía la casa, el nuevo dueño tendría que reconocer el censo y dar la renta al capellán, o podría redimir el censo dando el principal al que tuviera derecho a ese censo, que en el caso de una capellanía era el patrón de la misma.

Los fundadores de capellanías de Manila se sirvieron de diversos procedimientos para generar el capital con el que imponer los censos que sustentaron sus fundaciones. El cuadro 6 da una idea de cuáles fueron sus preferencias. Diez capellanías se fundaron con la intención de establecer una renta mientras viviera el fundador. Seis de esas fundaciones impusieron censos sobre las casas libres de censos en las que ellos vivían. En otros dos casos se impusieron censos sobre estancias a cierta distancia de la ciudad. Las otras capellanías se crearon cuando los fundadores hicieron su testamento, ya próximo el fin de sus vidas. Dieciocho de ellos vendieron sus bienes y de lo recaudado fundaron una capellanía. Entre los que legaron sus bienes para la capellanía, en dos casos dejaron solamente un quinto o los dos tercios de ellos, pero los otros declararon dejar todos sus bienes. Es de suponer que, cuando los fundadores dejaban sus bienes, la parte más importante de ellos era su casa, y eso es lo que mencionaron tres fundadores claramente, incluyendo lo que en ella se hallaba. Siete prefirieron dejar dinero al contado. Los otros dos casos del cuadro 6 en los que no se especifica la fuente del capital fueron dos personas que dejaron pagarés que les debían otros.

28 CMSXVII, fols. $182 \mathrm{r}-183 \mathrm{v}$. 
Cuadro 6. Procedencia del PRINCIPAl Para los Censos de las CAPELlanías

\begin{tabular}{|l|c|c|}
\hline \multicolumn{1}{|c|}{ Origen de los censos } & $\begin{array}{c}\text { En vida de los } \\
\text { fundadores }\end{array}$ & Próximos a la muerte \\
\hline Impuestos sobres sus propias casas o estancias & 10 & 3 \\
Por la venta de sus casas & & 3 \\
Venta de bienes, sin especificar & & 15 \\
Dinero & & 7 \\
Otros & 10 & 30 \\
\hline Total & & 30 \\
\hline
\end{tabular}

La documentación sobre capellanías manejada dio a conocer 70 censos provenientes de 41 capellanías, lo que corresponde a menos de dos por capellanía ${ }^{29}$. Aunque se fueron imponiendo poco a poco a través del siglo, en una ciudad relativamente pequeña como Manila, el número refleja su importancia económica. El número de censos por capellanía dependía de lo grande que fuera el principal. Cuanto mayor era el capital de la capellanía, mayor era la probabilidad de que se dividiera en varios censos. La media de todos los censos estudiados es de 1.366 pesos, una cantidad considerable que, en cierto modo, revela la capacidad financiera de Manila.

\section{CONCLUSIÓN}

El terremoto de 1645 causó daño a algunas de las casas que tenían impuestos censos con capitales de capellanías. Las fuentes usadas sólo mencionan seis casos, causando una devaluación en los valores de las casas y una reducción en la renta que tenía que pagar el censatario, que era lo que cobraban los capellanes. Por ejemplo el principal de 3.000 pesos de la capellanía del general Lorenzo de Torre se redujo a 444 pesos, y un censo de 1.000 pesos perteneciente a la capellanía de Francisca Leal se devaluó hasta los 128 pesos $^{30}$. Aunque las pérdidas del valor de los principales de los censos de capellanías no fueran muy grandes, el destrozo del terremoto dejó claro lo arriesgado que era ese tipo de inversiones. La suma del dinero de las obras pías administradas por la Hermandad de la Misericordia con censos impuestos en casas de la ciudad

29 De entre los 70 censos había 29 casas censadas para las capellanías que tenían otros censos previos, la mayoría solamente uno o dos, pero las hay con tres, cuatro y hasta cinco censos más sobre la misma propiedad, lo que confirma la importancia del censo en Manila.

30 CMSXVII, fols. 204v, 46r-50v. 
alcanzaba los 89.855 pesos antes del terremoto, pero se depreció a los 12.772 pesos después de los daños causados por esa calamidad ${ }^{31}$. Este contratiempo agravó los problemas demográficos que sufrió la población de Manila expuestos anteriormente, especialmente después de 1639, y aclara porqué hubo un descenso en la fundación de capellanías. El hecho de que se continuaran fundando capellanías y obras pías refleja el deseo de mantener una comunidad. Fundaron capellanías porque vivían allí y deseaban continuar viviendo allí, al igual que hacían sus paisanos y parientes en España y en México. Aún se puede decir más, como fin de este estudio y aunque ya no pertenezca a lo propuesto para este trabajo, y es que el poblamiento español en Manila tuvo suficiente capacidad de adaptación a los continuos escollos a los que se vio sometido. Coincidiendo más o menos con el fin del período de este estudio, las instituciones religiosas y benéficas que administraban las obras pías de los ciudadanos de Manila, con la Mesa de la Misericordia a la cabeza, buscaron nuevos métodos de financiación. Concretamente se dirigieron a los beneficios que podrían ganar en el comercio marítimo al prestar el dinero a mercaderes, sobre todo en el galeón de Acapulco, con intereses mucho más altos y unos plazos relativamente cortos. Es lo que llamaron las «obras pías de correspondencia o riesgos de mar», que sobrepasarían a los censos en el siglo XVIII como instrumentos de crédito en Manila ${ }^{32}$. Esta nueva estrategia irá de la mano de una recuperación gradual de la población de la ciudad.

\section{BIBLIOGRAFÍA}

Alva Rodríguez, Inmaculada, Vida municipal en Manila (siglos XVI-XVII), Córdoba, Universidad de Córdoba, 1997.

De la Costa, Horacio, S.J., The Jesuits in the Philippines, 1581-1768, Harvard University Press, Cambridge-Massachusetts, 1967.

Díaz-Trechuelo Spinola, Lourdes, «Religiosidad popular en Filipinas: Hermandades y cofradías (Siglos XVI-XVIII)», Hispania Sacra, LIII / 107 (Madrid, 2001): 345-366.

— «La Casa de la Misericordia de Manila», XI Congreso del Instituto Internacional de Historia del Derecho Indiano: Buenos Aires, 4 al 9 de septiembre de 1995: actas y estudios, vol. 4, Instituto de Investigaciones de Historia del Derecho, 1997: 71-90.

31 Uriarte, 1728: fol. 26v.

32 Schurz, 1985: 140-142. Díaz-Trechuelo, 1997, vol. 4: 75-90. 
— «Las Filipinas, en su aislamiento, bajo el continuo acoso», Historia General de España y América, vol. IX-2, Rialp, 1984: 129-153.

García-Abásolo, Antonio, «Population Movement in the Spanish Pacific during the $17^{\text {th }}$ century: Travellers from Spain to the Philippines», Revista Española del Pacífico, 19/20 (Madrid, 2006-2007): 133-151.

— «El mundo privado de los pobladores de la América española», Ámbitos, 16 (Córdoba, 2006): 17-30.

— «El poblamiento español de Filipinas (1571-1599)», Antonio García-Abásolo (ed.), España y el Pacifico, Córdoba, 1997: 145-155.

- «The private environment of the Spaniards in the Philippines», Philippine Studies, 44 (Manila, Third Quarter 1996): 349-373.

— «Inversiones indianas en Córdoba. Capellanías y patronatos como entidades financieras», Actas de las Segundas Jornadas de Andalucía y América, Andalucía y América en el siglo XVI, Sevilla, I, 1983: 427-543.

- «La expansión mexicana hacia el Pacífico: la primera colonización de Filipinas (1570-1580)», Historia Mexicana, XXXII / 125 (México D.F., 1982): 44-88.

García-Abásolo, Antonio y Peláez Portales, David, «Los beneficios de tener indianos. Inversiones de plata americana en la Campiña de Córdoba», Actas de las VII Jornadas sobre Historia de Montilla, Montilla, Exmo. Ayuntamiento, 2007: 19-58.

Gutiérrez, Lucio, O.P., The Archdiocese of Manila. A Pilgrimage in Time (1565-1999), vol. 1, Manila, The Catholic Archbishop of Manila, 1999.

Lavrin, Asunción, «Cofradías novohispana: economías material y espiritual», Pilar Martínez López-Cano, Gisela von Wobeser y Juan Guillermo Muñoz (ed.), Cofradías, capellanías y obras pías en la América colonial, México, UNAM, 1998: 49-64.

Levaggi, Abelardo, «Papel de los patronos en las capellanías. Cuestiones suscitadas a su respecto en el Río de la Plata», Pilar Martínez López-Cano, Gisela von Wobeser y Juan Guillermo Muñoz (ed.), Cofradias, capellanías y obras pías en la América colonial, México, UNAM, 1998: 143-154.

Manchado López, Marta M.a «Chinos y españoles en Manila a comienzos del siglo XVII», Miguel Luque Talaván y Marta M. ${ }^{a}$ Machado López (ed.), Un océano de intercambios: Hispanoasia (1521-1898). Homenaje al Profesor Leoncio Cabrero Fernández, vol. I, Madrid, 2008: 141-159.

Martínez López-Cano, Pilar, Von Wobeser, Gisela y Muñoz, Juan Guillermo, (ed.), Cofradias, capellanias y obras pías en la América colonial, México, UNAM, 1998.

Martínez López-Cano, María Pilar, «Crédito y capellanías en la ciudad de México, 1620-1646», María del Pilar Martínez López-Cano, Elisa Speckman Guerra y Gi- 
sela von Wobeser (ed.), La Iglesia y sus bienes. De la amortización a la nacionalización, México, Instituto de Ciencias Históricas, UNAM, 2004: 137-156.

- El crédito a largo plazo en el siglo XVI, Ciudad de México (1550-1620), México, Universidad Nacional Autónoma de México, 1995.

Mateo Seco, Lucas Francisco, «Purgatorio», Gran Enciclopedia Rialp, vol. XIX, Madrid, 1974: 507-511.

Merino, Luis, O.S.A., Arquitectura y urbanismo en el siglo XIX, Manila, The Intramuros Administration, 1987.

- El cabildo secular: Aspectos fundacionales y administrativos, Manila, The Intramuros Administration, 1983.

Montero Recorder, Cyntia, «La capellanía: una de las prácticas religiosas para el más allá», Pilar Martínez López-Cano, Gisela von Wobeser y Juan Guillermo Muñoz (ed.), Cofradías, capellanías y obras pías en la América colonial, México, UNAM, 1998: 131-142.

Muñoz Correa, Juan Ignacio, «Las estrategias de una elite frente a la tierra y el cielo», Pilar Martínez López-Cano, Gisela von Wobeser y Juan Guillermo Muñoz (ed.), Cofradías, capellanías y obras pías en la América colonial, México, UNAM, 1998: 155-171.

Pniover, Segismund, Pious Trust Funds in the Archdiocese of Manila. A Coordinated Compilation of Sources. Manuscrito. Manila, 1954.

Santiago, Luciano P. R., Laying the Foundations: Kapampangan Pioneers in the Philippine Church, 1592-2001, Angeles City, Holy Angel University, 2001.

- «The First Filipino Capellanías (1605-1699)», Philippiniana Sacra, XXII / 66 (Manila, Sept.-Dec., 1987): 421-434.

Schurz, William Lytle, The Manila Galleon, Historical Conservation Society, Manila, 1985 (la versión original es de 1939).

Uriarte, Juan Baptista, Manifiesto y Resumen Histórico de la Fundación de la Venerable Hermandad de la Santa Misericordia de la Ciudad de Manila, Hospital, Casa y Collegio de Niñas, y Iglesia de Santa Ysabel..., Manila, Colegio y Universidad de Santo Tomas, 1728.

Villaroel, Fidel, O.P., "The "Colegio de Santo Tomas", Forerunner of the UST Central Seminary», Philippiniana Sacra, XXXVII / 111 (Manila, Sept.-Dec., 2002): 523-544.

Von Wobeser, Gisela, «Las capellanías de misas: su función religiosa, social y económica en la Nueva España», Pilar Martínez López-Cano, Gisela von Wobeser y Juan Guillermo Muñoz (ed.), Cofradias, capellanías y obras pías en la América colonial, México, UNAM, 1998: 119-130. 


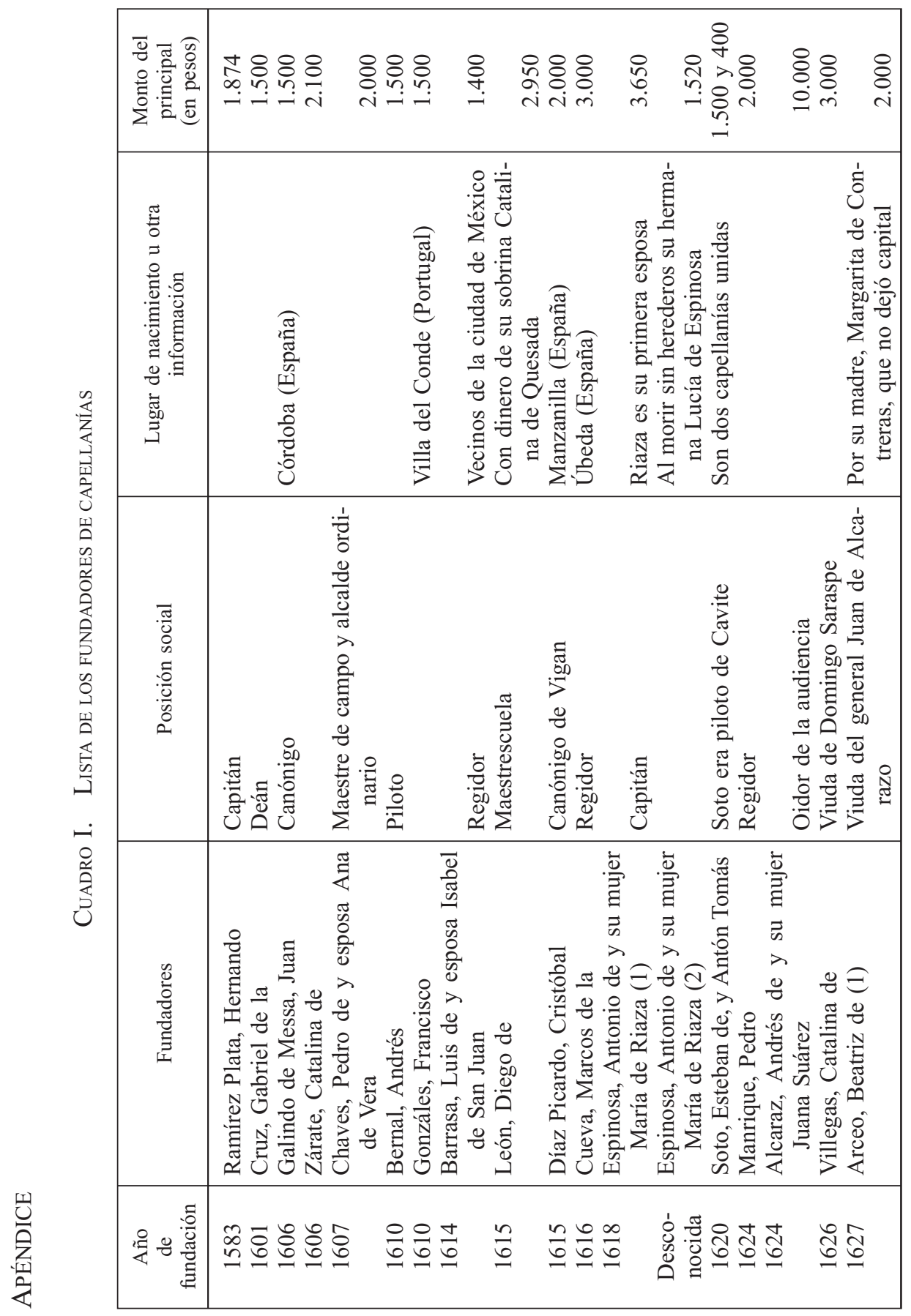




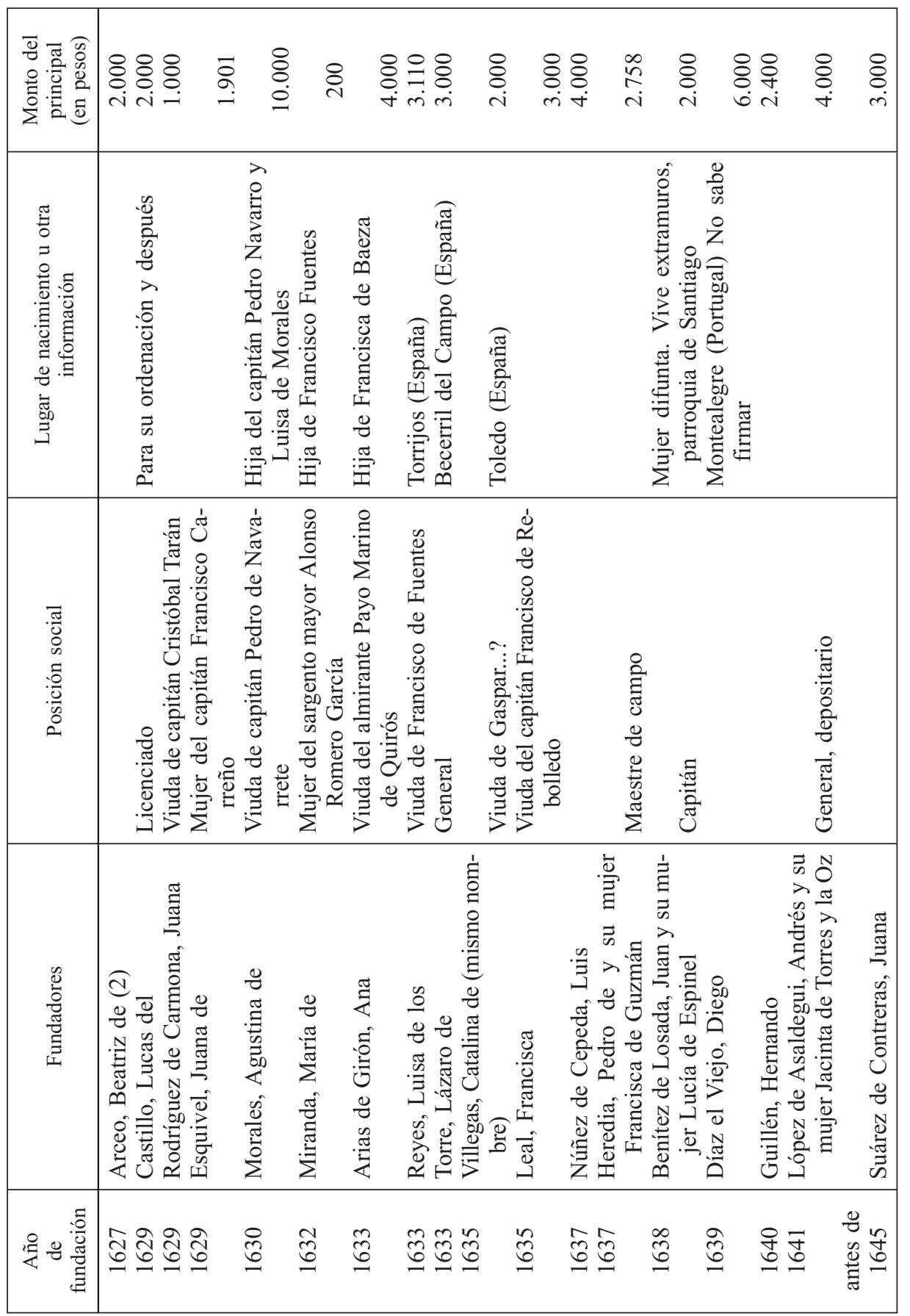




\begin{tabular}{|c|c|c|c|c|c|c|c|c|c|}
\hline 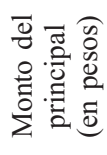 & $\begin{array}{l}\infty \\
\stackrel{\infty}{0} \\
-\end{array}$ & \&̊ㅜㅁ & 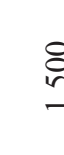 & 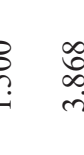 & 8 & छ̊ & 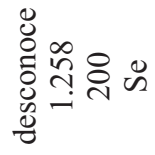 & 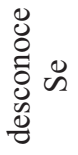 & $\begin{array}{l}8 \\
0 \\
0 \\
0 \\
0 \\
0 \\
0 \\
0\end{array}$ \\
\hline 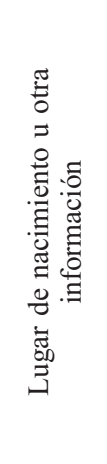 & & 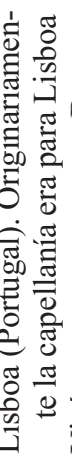 & 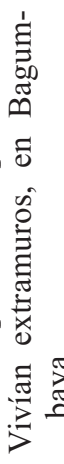 & 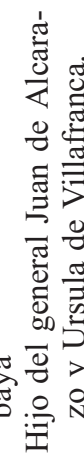 & & 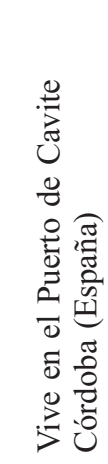 & 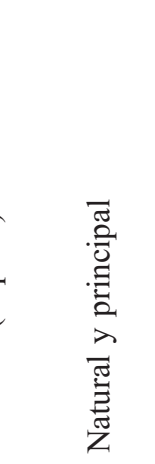 & & \\
\hline 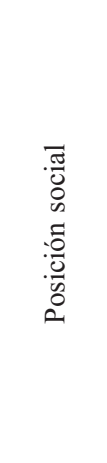 & \multicolumn{6}{|c|}{ 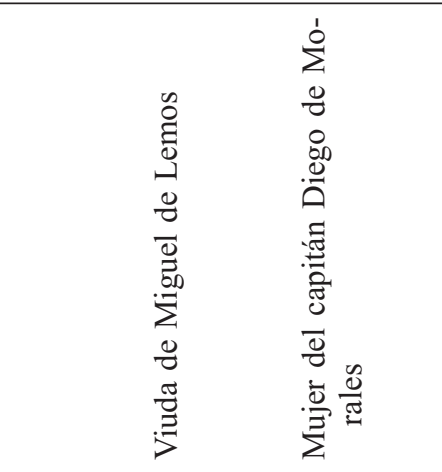 } & \multicolumn{2}{|l|}{ 苂 } & \\
\hline 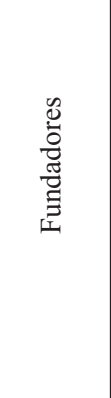 & \multicolumn{2}{|c|}{ 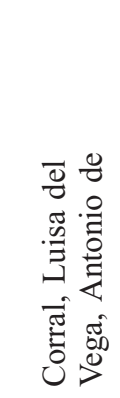 } & \multicolumn{2}{|r|}{ 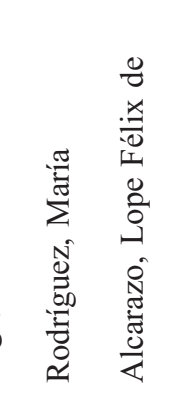 } & 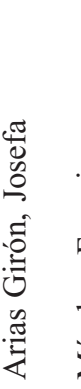 & 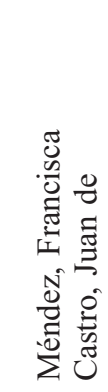 & 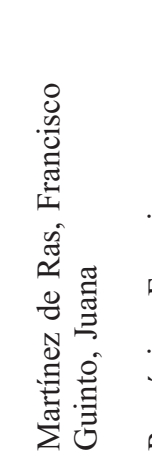 & 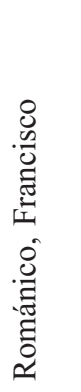 & 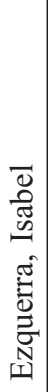 \\
\hline 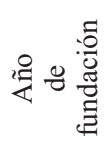 & 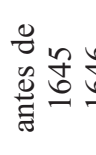 & & $\stackrel{\infty}{\mathbb{J}}$ & 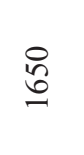 & $\underset{n}{\stackrel{2}{0}}$ & \begin{tabular}{l}
\multirow{2}{*}{$n$} \\
6 \\
6
\end{tabular} & 유: & 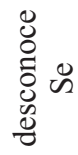 & $\begin{array}{l}0 \\
0 \\
0 \\
0 \\
0 \\
0 \\
0\end{array}$ \\
\hline
\end{tabular}

Revista de Indias, 2010, vol. LXX, n. ${ }^{\circ} 249,469-500$, ISSN: 0034-8341

doi:10.3989/revindias.2010.015 


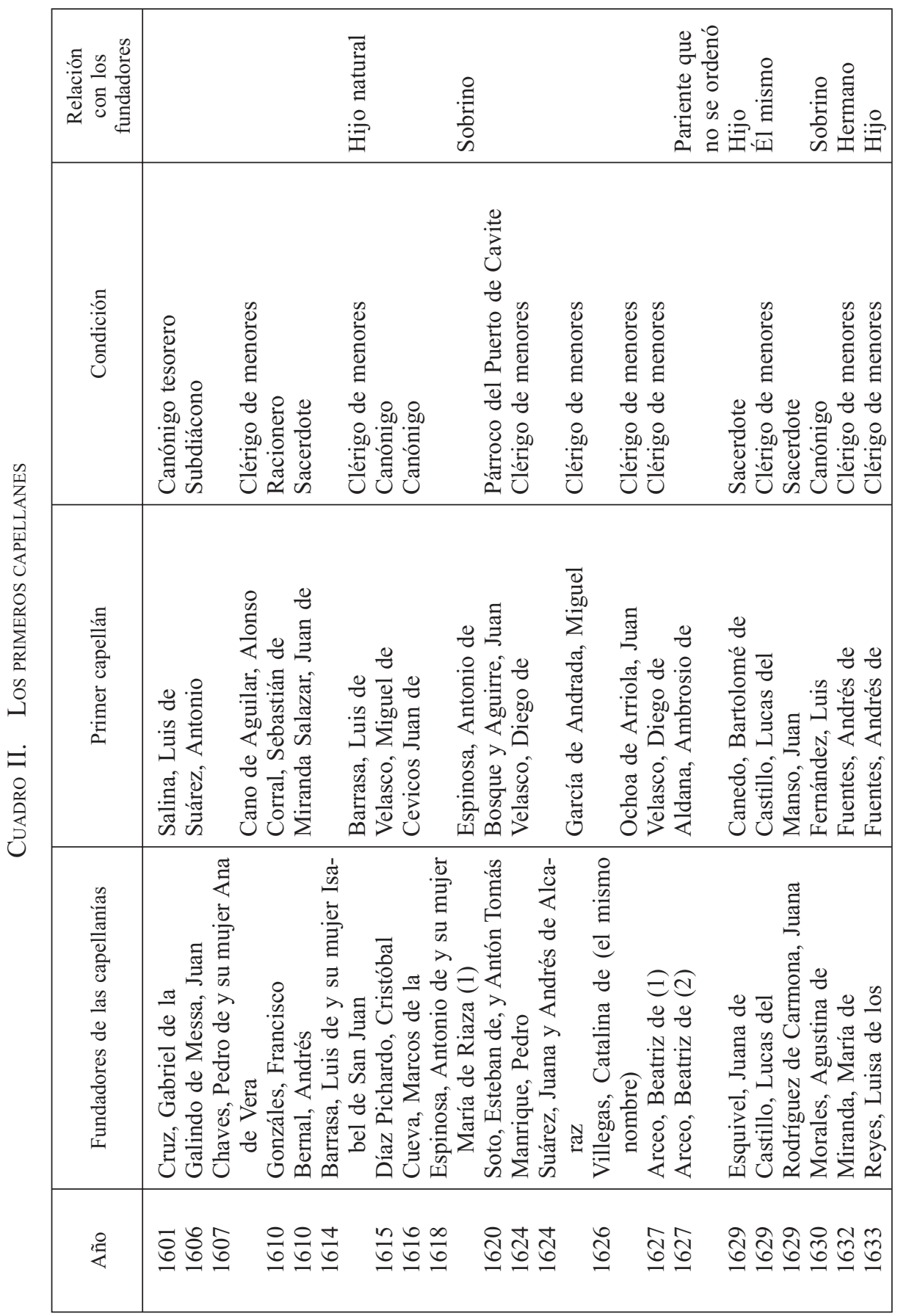




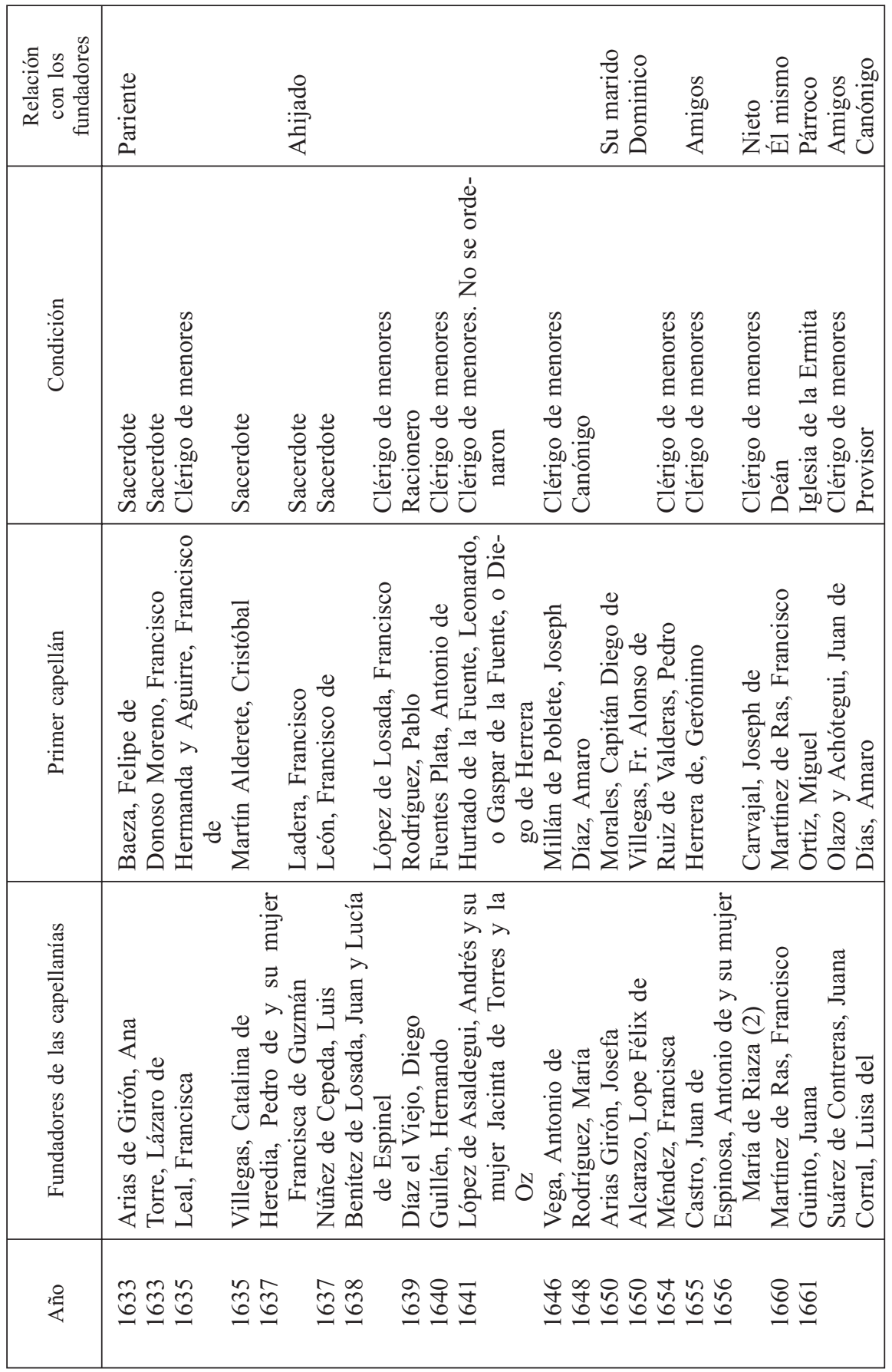




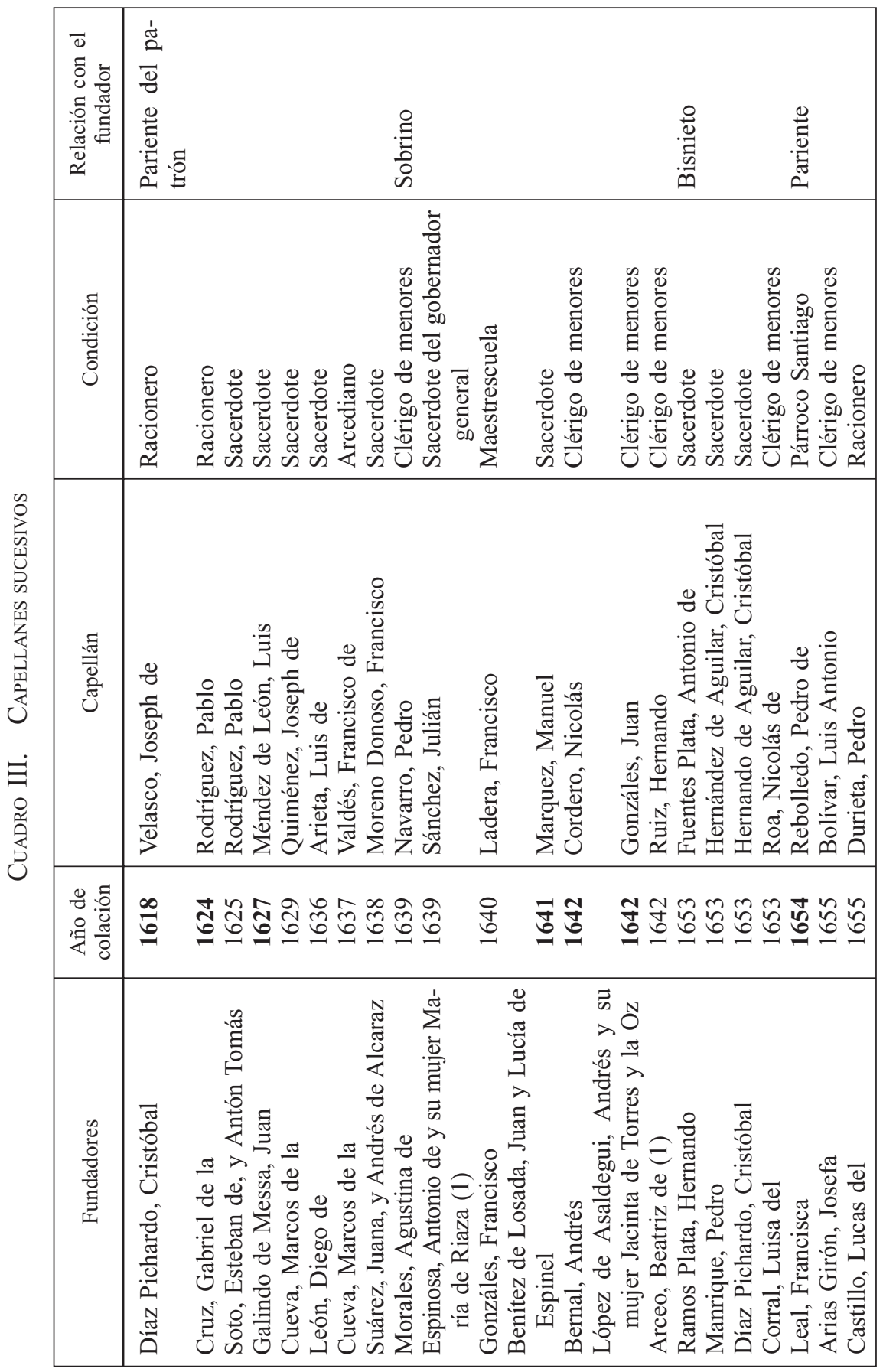




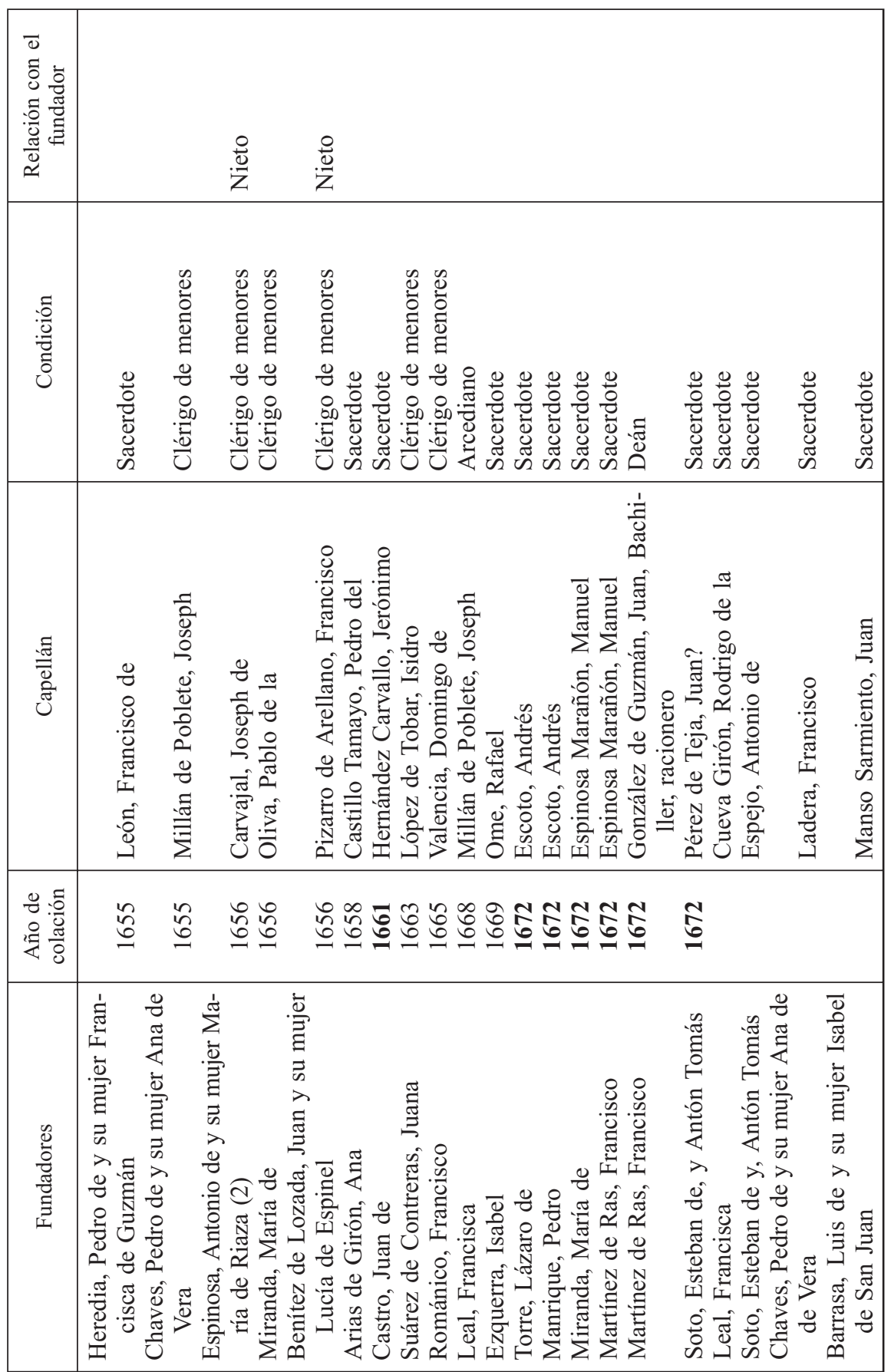




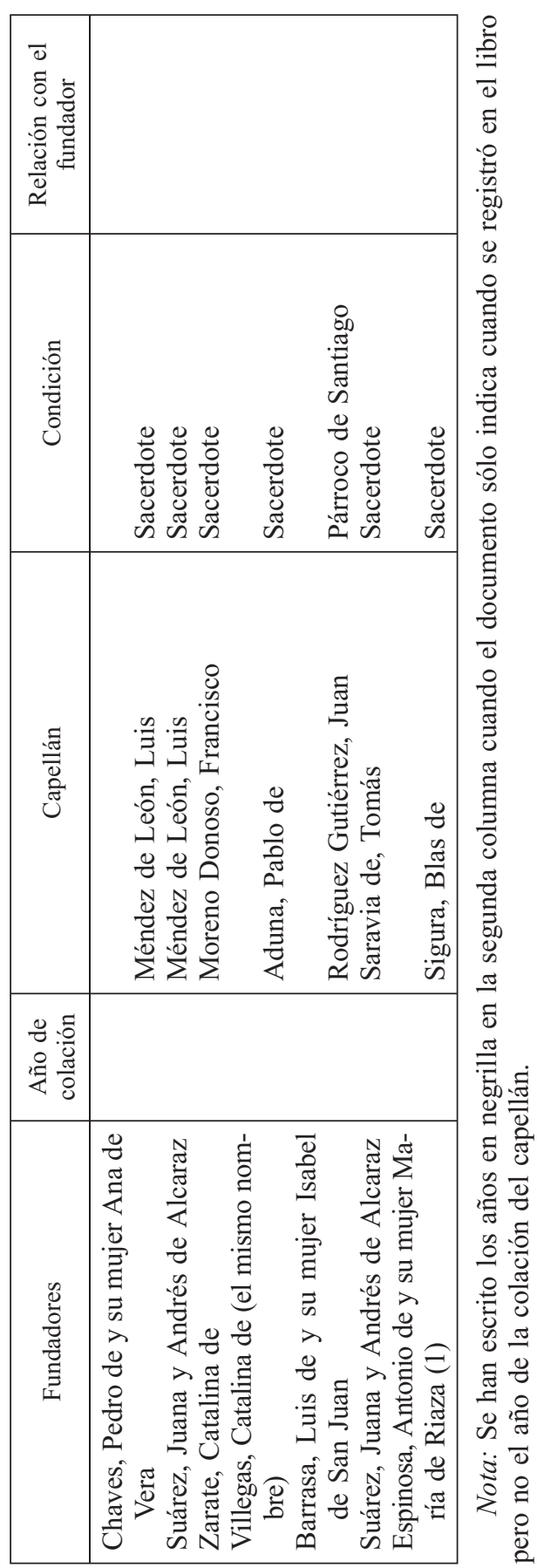


Fecha de recepción: 1 de julio de 2008

Fecha de aceptación: 12 de marzo de 2009

\section{THE POPULATION OF MANILA AND THE CAPELLANÍAS OF THE SPANIARDS: REGISTRY BOOK, 1642-1672}

This study focuses on the characteristics of the capellanías of Manila until 1672. The main source for this work is a registry book of capellanías. The quantitative and qualitative information gathered is useful to study the development of this institution, and to learn new insights on the demography, society, culture, and economy of the Spanish population of Manila during most of the seventeenth century. Among the findings of this study, it stands out the efforts carried out and the difficulties found in order to attain a Creole clergy.

KeY WORDS: Manila, $17^{\text {th }}$ century, capellanías, Spaniards, Creole clergy. 